\title{
A conceptual model for physician-system integration: A scoping review
}

\author{
Ann M. Nguyen*1, Suzanne J. Wood ${ }^{2}$, Christopher E. Johnson ${ }^{3}$, William L. Dowling ${ }^{2}$ \\ ${ }^{1}$ School of Medicine, New York University, United States \\ ${ }^{2}$ School of Public Health, University of Washington, United States \\ ${ }^{3}$ School of Public Health and Information Sciences, University of Louisville, United States
}

Received: July 31, 2019

DOI: $10.5430 /$ jha.v8n5p34
Accepted: August 23, 2019

Online Published: September 4, 2019

\begin{abstract}
Despite the widespread pursuit of physician-health system integration, the evidence for factors affecting successful integration is uncertain and inconclusive. We sought to identify and categorize the organizational factors in the current landscape of physician-health system integration. We conducted a scoping review of the empirical literature on this topic, first surveying the theoretical perspectives that have been used in past studies in order to determine how theory has been used to explain and predict changing integration strategies over time. Second, we extracted factors that have been used to define the environment, physician group, hospital, care coordination, and health system success. From the 29 eligible articles, bargaining-market power theory and transaction cost theory were the predominant theories applied. We identified 48 organizational factors that comprise the landscape of physician-system integration. Our findings cumulated in a conceptual model that may help health care executives, policymakers, and researchers more effectively address the complexities of integration.
\end{abstract}

Key Words: Physician-system integration, Scoping review, Conceptual model

\section{INTRODUCTION}

Despite the widespread pursuit of physician-health system integration, the evidence for factors affecting successful in tegration is mixed and inconclusive. This is in part due to the absence of a universal definition of integration ${ }^{[1]}$ and an overabundance of definitions for success. ${ }^{[2]}$ This article summarizes the findings of a scoping review of the organizational factors affecting the integration of physician groups with hospitals and health systems, herein referred to as "physician-system integration."

Physician groups, hospitals, and health systems have historically viewed integration as a mutually beneficial relationship. Integration was seen as a means of gaining economic and operational efficiency, lowering transaction costs, ${ }^{[3]}$ increasing bargaining power against payers ${ }^{[4]}$ improving quality, increasing access, and streamlining care coordination. ${ }^{[3,5]}$ However, the evidence on the value of integration is mixed. Physician-system integration has been shown to increase physician accountability and satisfaction, ${ }^{[6]}$ while having a positive or null effect on the financial status of a health system. ${ }^{[7-10]}$ Other studies, however, have linked integration to no changes in clinical outcomes ${ }^{[11]}$ and quality, ${ }^{[12]}$ as well as financial loss. ${ }^{[11,13-15]}$

The trend toward integration continues upward regardless of mixed findings, re-fueled by the prospect of risk-based payment approaches ${ }^{[16,17]}$ and the race to create accountable

\footnotetext{
*Correspondence: Ann M. Nguyen; Email: ann.nguyen@nyulangone.org; Address: School of Medicine, New York University, New York, NY, 10016, United States.
} 
care organizations (ACOs), both of which rely on collaboration between physicians and hospitals. In 2002, 27\% of U.S. hospitals reported having no affiliation with physicians, beyond their traditional medical staff model. In 2012, only $19 \%$ of hospitals remained unaffiliated with physicians. ${ }^{[12]}$ In 2013, two-thirds of physicians reported that they expected integration to continue to increase. ${ }^{[18]}$

\subsection{New contribution}

Given the impetus toward increased physician-system integration, it is important for health care executives, policymakers, and researchers to effectively address the complexities of integration. Our review supplements and extends previous overviews ${ }^{[2,17,19,20]}$ to address the research question, "What organizational factors are used to measure the success of physician-system integration for different physician integration models?" Our objectives were two-fold:

1) To survey the organizational theories used in past studies to determine how theory has been used to explain changing integration strategies over time.

2) To create a conceptual model that captures how researchers have examined this complex relationship.

Consistent with these objectives, there are two primary products of the review. First, we contribute to the knowledge on organizational theory application to physician-system integration, highlighting the theories that have been used most often to explain and predict this relationship. Second, we contribute to the conceptual understanding of integration by creating a model that summarizes the past empirical research.

\section{Methods}

\subsection{Conceptual model}

The complexity of management practice often requires explanations that are equally as complex. ${ }^{[21]}$ The landscape of physician-system integration is no exception. We thus drew upon three organizational theories and frameworks - vertical integration theory, open systems theory, and Porter's Value Chain - to approach the scoping review and development of the conceptual model.

\subsubsection{Vertical integration theory}

We employed vertical integration theory, which posits that the key players in integration arrangements are hospitals, physicians, and payers, along with the ways in which they are structurally and/or financially organized (i.e., via an accountable care organization [ACO] and/or health system). ${ }^{[22]}$ The entities in our model correspond roughly with the key players.

Published by Sciedu Press

\subsubsection{Open systems theory}

Next, we considered the external environment by employing open systems theory. ${ }^{[23]}$ The environment consists of political, economic, social, technological, environmental (i.e., climate), and legal forces. Through a continuous feedback-loop, healthy open systems will often interact and try to influence the environment through use of public relations, advertising, marketing, lobbying, cooptation, and advocacy. In the context of physician-system integration, the system typically consists of the key players in integration, which are hospitals, physicians, and payers, along with the ways in which they are structurally and/or financially organized. ${ }^{[3,22,24]}$

\subsubsection{Value chain}

To operationalize the internal environment, we employed the Value Chain ${ }^{[25,26]}$ to describe the processes of care delivery. The Value Chain utilizes a systems approach, where each "link" in the chain is designed to add value to the original input. The service delivery chain is the fundamental value creation stream, which includes activities that occur pre-service (such as marketing research, services offered and branded, pricing, promotion, and distribution/logistics); point-of-service (clinical operations); and after-service (follow-up, billing, and follow-on). The support activities chain facilitates and improves the service delivery chain through organizational structure (function, division, and matrix), organizational culture (shared assumptions, values, and norms), and strategic resources (financial, human, informational, and technological).

Using the three theories and frameworks, we created a primary coding schema comprised of the environment (political, economic, social, technological, environmental, and legal forces), physician group (organizational structure, organizational culture, strategic resources), hospital (organizational structure, organizational culture, strategic resources), care coordination (pre-service, point-of-service, after-service), and health system success (all parts of the Value Chain).

\subsection{Qualitative approach}

For our scoping review, ${ }^{[27]}$ we started with the article retention protocol shown in Figure 1. We searched PubMed, ProQuest, and EBSCO for articles published between January 1, 2005 and December 31, 2016 using the terms: "physician-system integration", "physician integration", "hospital integration", "integrated health system", "integrated health delivery system", "physician-hospital integration", "physician-hospital affiliation", "physician alignment”, "physician-hospital alignment", "physician-system alignment", "physician-hospital arrangement", "physiciansystem arrangement", and "clinical integration". We specified the time frame to target the current health care climate, 
i.e., six years prior to and following the Affordable Care Act. This process returned 621 unique, English-language articles. Citations were downloaded into the EndNote $\mathbb{R}$ citation manager. ${ }^{[28]}$ We then evaluated abstracts to determine if the article was:

(1) An empirical research piece (i.e., published in a peerreviewed journal, not a perspective or theoretical piece);

(2) From the U.S. (i.e., discusses at least one U.S.-based example of integration);

(3) Discusses at least one type of physician integrating structure (i.e., see Appendix A for the list of physicians integrating structures and their definitions).

This process returned 40 articles. We reviewed the full text of these 40 and repeated the analysis to further remove any not meeting the criteria, resulting in 21 articles. Finally, we reviewed the bibliographies to identify relevant articles $(\mathrm{n}=$ 8), resulting in 29 articles.

Using the coding schema, we coded variables used to measure the environment, physician group, hospital, care coordination, health system success, and organizational theories applied. The coding team consisted of two co-authors, with a third co-author available to provide a tie-breaking decision. Finally, using axial coding ${ }^{[29]}$ and investigator triangulation, in which two skilled researchers with different disciplinary perspectives examined the same data, ${ }^{[30]}$ we aggregated the coded variables into organizational factors that nested within open systems theory and the Value Chain. All coding was

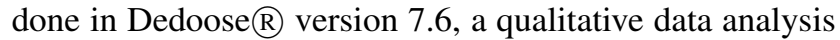
program. ${ }^{[31]}$

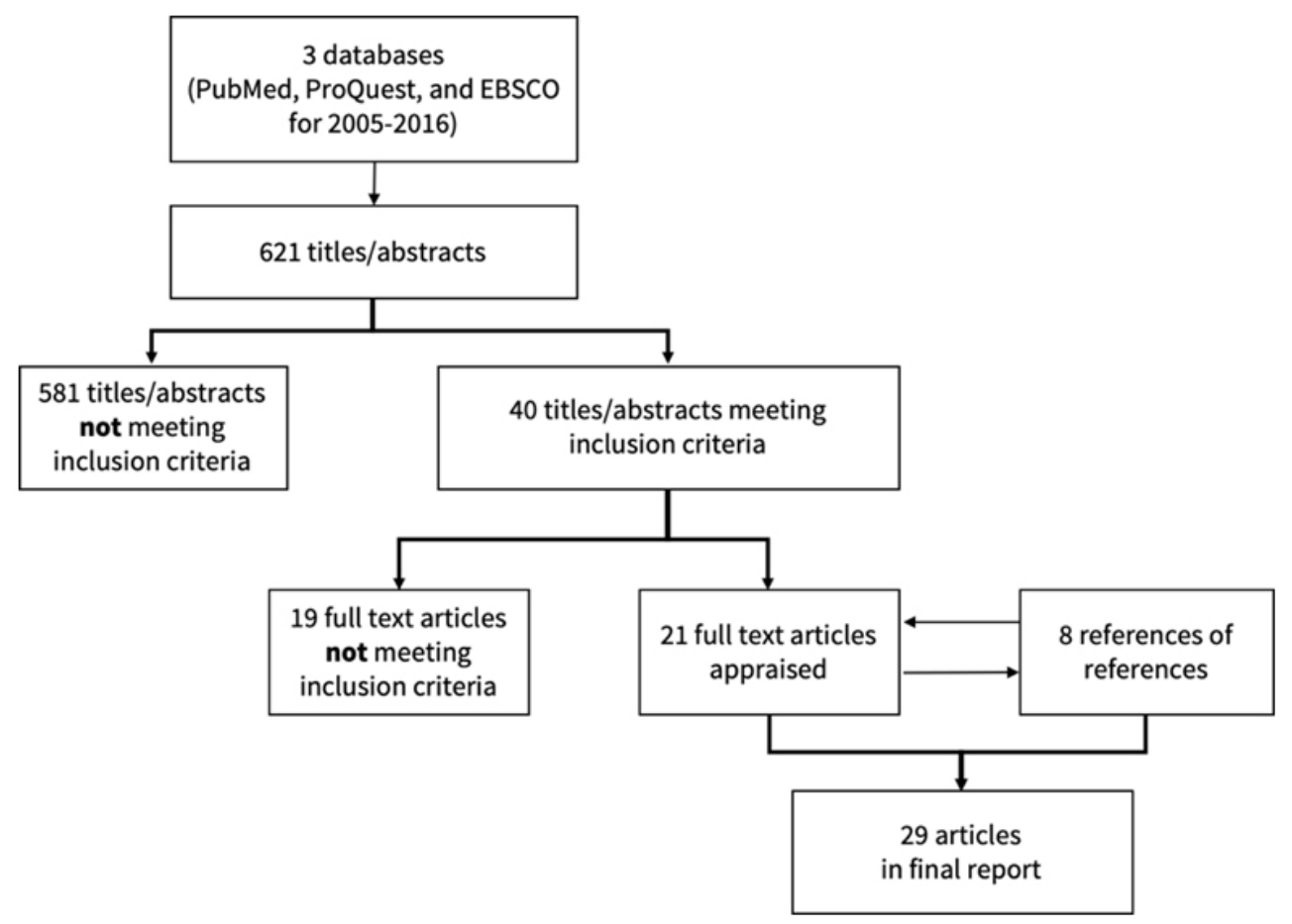

Figure 1. Article retention protocol

\subsection{Quantitative approach}

Health system success can be defined in many different ways. ${ }^{[2]}$ Using health system success data from the scoping review, we performed a cluster analysis, an exploratory technique for dividing a multivariate dataset into natural clusters, in order to group the success factors into more meaningful clusters. We created a database that listed all identified success factors $(n=146)$ and the number of times each was used in tandem with an organizational factor drawn from the Value Chain (see Appendix B).

We then conducted a hierarchical cluster analysis to classify the health system success factors into meaningful clusters. ${ }^{[32]}$ We applied the Ward (1963) method, which minimizes the within-cluster variation and produces clusters of roughly similar size. To determine the number of clusters, we applied variations of two to six clusters and checked the quality of the results. We employed MANOVA, ANOVA, and regression techniques to confirm the uniqueness of each cluster. This type of analysis had been used in other health care studies to form exploratory groups based on organizational dimensions. ${ }^{[33-35]}$ Quantitative analysis was done using Stata 13 . $^{[36]}$ 


\section{Results}

Appendix $\mathrm{C}$ provides a summary of the 29 identified articles' study setting, study period, organizational theories, and organizational factors.

\subsection{Use of organizational theories}

Our first objective was to survey the theoretical theories used in past studies to determine their historical use to explain and predict physician-system integration over time. Only 11 $(37.9 \%)$ of the articles explicitly called upon organizational theory to guide their hypotheses or approaches.

The two most cited theories were transaction cost theory ${ }^{[60,61]}$ and bargaining-market power theory. ${ }^{[62]}$ Transaction cost was a commonly-cited aspect of both open systems theory and the Value Chain, which explained and predicted a firm's decision to outsource or internalize production of a good or service (i.e., if it will "make-or-buy") to minimize the cost of a transaction. In the context of physician-system integration, this theory was a useful tool in explaining and predicting whether health systems would vertically integrate with physician groups. For example, a hospital may decide to "buy" a primary care group to minimize the transaction cost of patient referrals from those primary care physicians.

Bargaining-market power theory, another open systems theory based in economics, was popularized in the context of physician-system integration by Gal-Or. ${ }^{[62]}$ The theory posited that an entity with more market power had greater bargaining power. A physician group or hospital with more market power could charge higher prices for health services. Gal-Or demonstrated that the existence of incentives for vertical mergers between health systems and physician groups depended on the relative degree of competitiveness of their respective markets. When the degree of competitiveness was comparable, a vertical merger enhanced the bargaining position of both vis-a-vis insurers. In contrast, when one firm's market was much more competitive than the other, a vertical merger could reduce the joint profits of the merged entity.

\subsection{Development of conceptual model}

The second objective of this study was to develop a conceptual model that captures how researchers have examined the complex relationship of physician-system integration. We extracted 48 organizational factors that had been used to measure the environment, physician group, hospital, care coordination, and health system success. Most articles employed factors of the environment ( $86.2 \%$ of articles), physician group (100\%), hospital (79.3\%), and success $(89.7 \%)$. Only $24.1 \%$ used care coordination. Appendix D gives a breakdown of the number of articles that cited each factor and the average number of factors per article.

\subsubsection{Environment}

We identified six environmental factors that impacted the entire health system and how each player approached integration: (1) health reform; (2) market structure; (3) competition; (4) market demographics; (5) regulations; and (6) technology.

Health Reform. Often driven by public pressure to improve aspects of safety and quality, health reform was federal policy that affected the nature and degree of integration. ${ }^{[17]}$ Such policies included Medicare payment reform, which researchers posited to influence integration by facilitating the re-organization of care delivery and the re-financing of care. Another example of health reform was Meaningful Use, a federal initiative for funding electronic health records (EHRs), as the cost and potential for EHR improvement could be a decisive factor for physician groups contemplating integration. ${ }^{[49]}$

Market Structure. We found market structure to be another key environmental factor. Market structure included the presence of and relationship between major players of integration. These players were typically physicians, hospitals, health systems, purchasers, payers, managed care organizations, and ACOs, with their interactions to one another determined by restrictions such as market malpractice rates and incentive programs. ${ }^{[17,40]}$

Competition. As physician-system integration is ultimately a business venture, competition was defined as how players in the market actively responded to increased mergers of physician groups with hospitals and private firms. ${ }^{[39]}$ This factor was most commonly measured using the HerfindahlHirschman Index (HHI), an economic measure that compared the size of a firm (i.e., physician, hospital, insurance, and payer) to its market in a given area

Market Demographics. The most widely used environmental factor was market demographics, which broadly encompassed the patient and payer mix of a health system's service area. Measures of individual-level patient demographics included: age, gender, race, income, education, geographic location (e.g., distance to hospital), insurance coverage, and health status). At a greater contextual level, measures of the population included: metropolitan statistical area (or rurality) and the physician-to-population ratio.

Regulations. Regulations were another form of government policy, more specific to aspects of health organizations. Health care-specific regulations included the Health Insurance Portability and Accountability Act (HIPAA), which was a privacy protection law; the Stark Law, which governed physician self-referral for Medicare and Medicaid pa- 
tients; the Emergency Medical Treatment and Labor Act, which required hospitals participating in Medicare to maintain emergency room coverage; quality control regulations; anti-trust regulations and related FTC and DOJ investigations on physician-hospital alliances; and laws prohibiting hospital employment of physicians. There were also non-health care regulations that could impact physician-system integration, such as: federal anti-kickbacks, electronic discovery laws, IRS laws and regulations, and the Safe Harbor Law.

Technology. Technological advances were starting to move care away from the hospital either to the post-acute or outpatient setting. ${ }^{[17,39,44]}$ Technology influenced where physician groups and hospitals directed their resources. Per open systems theory, technological advances that required more resources than were available to these organizations may provoke them to solicit government support and subsidies (e.g., via Meaningful Use) or look to "buy" resources through integration.

\subsubsection{Physician group}

The physician group of interest in this study was the physician group being considered for integration with a hospital. Using the three support activities of the Value Chain as our framework, we identified thirteen physician group factors that should be considered in a decision for integration. Table 1 gives the definitions of each factor, along with variables we found in the literature that had been used to measure them.

Organizational Structure. Organizational structure was one aspect of an organization that enabled the value creation for patients. Organizational structure was described using physician group factors: care delivery structures; practice type; integration structures; physician composition; leadership; and governance. Of note, we found that integrating structure, which was the contractual mechanism through which a physician group was aligned with a hospital or health system, was measured in a multitude of ways, sometimes using variables that have overlapping definitions. Most articles employed one (or all) of the classifications defined by the American Hospital Association. Other articles collapsed integrating structures into broader categories. ${ }^{[5,58]}$ We also noted that leadership and governance were challenging to measure, as indicated by the lack of specific variables relative to the propensity for them to be stressed as important factors of successful integration.

Organizational Culture. Organizational culture was the overarching, internal environment within which an organization operates. ${ }^{[26]}$ Organizational culture was described using the factors: physician culture; mission, vision, and values; and transparency. The reviewed articles sought to find alignment between the these factors with their counterparts on the hospital side. ${ }^{[46,50]}$ Researchers also honed in on the generational culture shift of the physician workforce, in which younger physicians now have higher expectations for worklife balance, ${ }^{[17,40,44,49,50]}$ no longer seeing the hospital as their social center.

Strategic Resources. Strategic resources were the valuecreating, tangible and intangible resources necessary for the delivery of health services. ${ }^{[26]}$ The factors of strategic resources included: compensation and incentives; tangible resources; strategies; and information technology. Strategic resources were considered from both the monetary and nonmonetary standpoints, often playing a critical role in the bargaining and market power of a physician group. For example, physician groups considering alignment with hospitals often also considered the compatibility of their respective EHR systems, which affected the coordination of care. ${ }^{[38,43,44]}$

\subsubsection{Hospital}

In this study, we were interested in hospitals that are part of health systems. Once again, we used the support activities of the Value Chain as our framework, identifying twelve hospital factors that should be considered in the decision to integrate a physician group. Table 2 gives the factor definitions and associated variables found in the literature.

Organizational Structure. For the hospital, organizational structure can be described using the following factors: care delivery structures; hospital type; size; leadership; and governance. We found that researchers often used publiclyavailably information to measure some of these factors. For example, hospital type, which was the organizational designation of the hospital, could be measured by its metropolitan service area designation. This designation was important, as rural hospitals often had less bargaining power against their limited supply of physicians. ${ }^{[13,37,41,47,54,57,58]}$

Organizational Culture. The hospital had a wider breadth of personnel than the physician group, making the organizational culture of a hospital the more complex of the two. Cultural factors included: hospital culture; mission, vision, and values; and transparency. We found that organizational culture had a lot to do with trust in the leadership, ${ }^{[39,43,46,50]}$ which had trickle-down effects on the treatment of patients, treatment of employees, and physician referral patterns. ${ }^{[46]}$

Strategic Resources. The hospital's strategic resources could serve as leverage for hospitals aiming to integrate a physician group, as greater quality and quantity of resources was postulated to reduce transaction costs between services. Broadly, the organizational factors of strategic resources were: patient and payer mix; tangible resources; strategies; and information technology. Strategic resources were often considered 
separately for the pre- and post-integration phases. ${ }^{[17,39,43]}$ The hospital also considered patient and payer mix as a preintegration strategic resource, a resource that did not appear on the physician group side. This was likely due to the hos- pital's reach being typically greater than that of a physician group, which they can use to tempt a physician group.

Table 1. Physician group organizational factors affecting physician-system integration

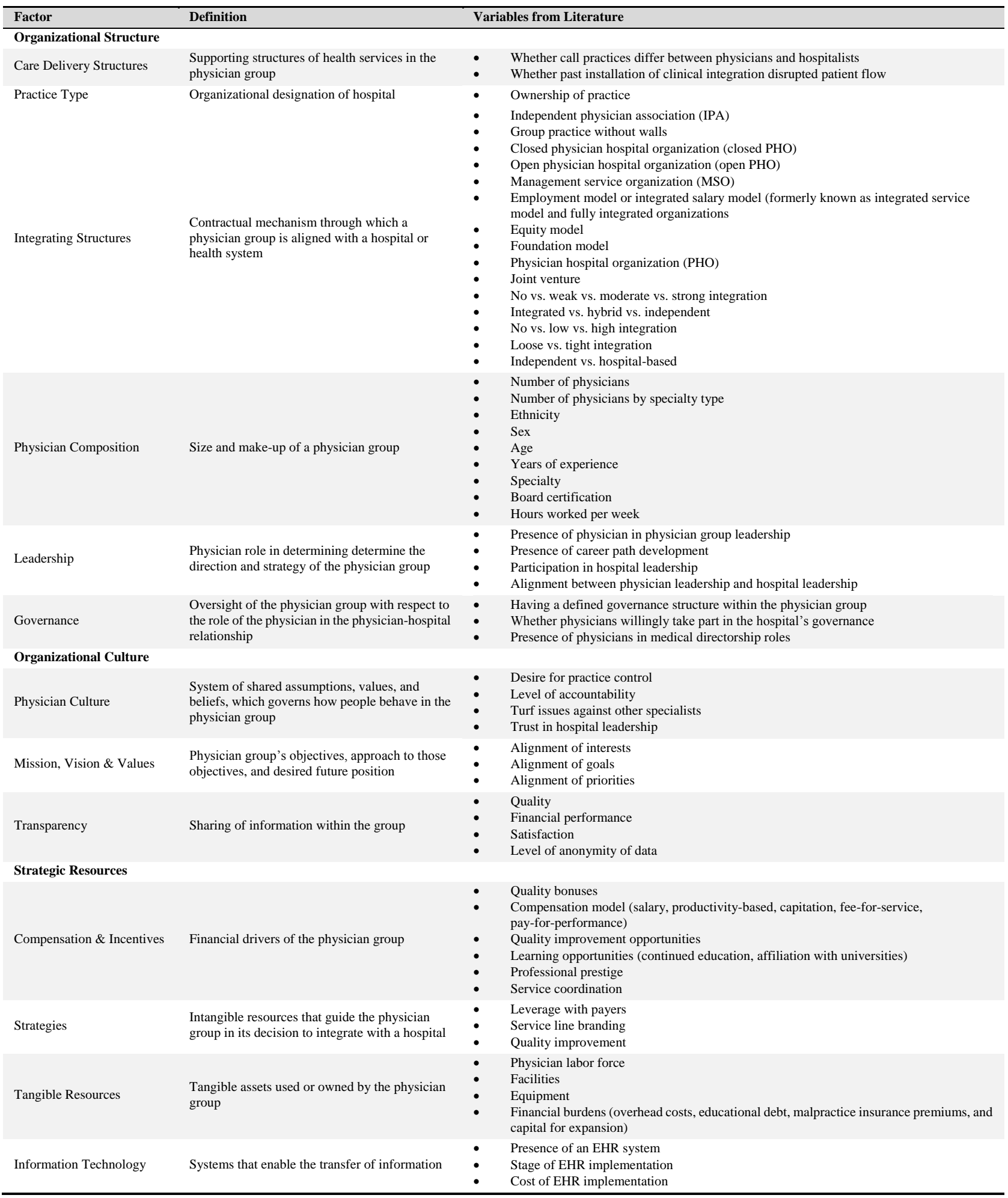


Table 2. Hospital organizational factors affecting physician-system integration

\begin{tabular}{|c|c|c|}
\hline Factor & Definition & Variables from Literature \\
\hline \multicolumn{3}{|c|}{ Organizational Structure } \\
\hline $\begin{array}{l}\text { Care Delivery } \\
\text { Structures }\end{array}$ & $\begin{array}{l}\text { Supporting structures of health services in the } \\
\text { hospital }\end{array}$ & $\begin{array}{ll}- & \text { Service mix } \\
\text { - } & \text { Specialty lines } \\
\text { - } & \text { How hospitalists are used } \\
\text { - } & \text { Whether the OR schedule is manageable } \\
& \text { Availity of an MRI service }\end{array}$ \\
\hline Hospital Type & Organizational designation of hospital & $\begin{array}{ll}- & \text { Teaching status } \\
& \text { Designation as a specialty hospital } \\
\text { - } & \text { Designation as an acute care hospital } \\
\text { - } & \text { Runership (non-profit status) } \\
\text { - } & \text { Network or system membership }\end{array}$ \\
\hline Size & Patient capacity & $\begin{array}{ll}\text { - } & \text { Number of beds (small }<100 \text { beds; medium } 100-300 ; \text { and large }>300 \text { ) } \\
\text { - } & \text { Number of staffed beds } \\
\text { - } & \text { Number of outpatient visits } \\
\text { - } & \text { Number of total admissions } \\
& \text { Inpatient growth }\end{array}$ \\
\hline Governance & $\begin{array}{l}\text { Oversight of the hospital with respect to the role } \\
\text { of the physician in the physician-hospital } \\
\text { relationship }\end{array}$ & $\begin{array}{l}\text { - Having a defined governance structure within the hospital } \\
\text { - Whether physicians willingly take part in the hospital's governance }\end{array}$ \\
\hline \multicolumn{3}{|c|}{ Organizational Culture } \\
\hline Hospital Culture & $\begin{array}{l}\text { System of shared assumptions, values, and } \\
\text { beliefs, which governs how people behave in } \\
\text { the hospital }\end{array}$ & $\begin{array}{ll}\text { - } & \text { Trust } \\
\text { - } & \text { Level of formality } \\
\text { - } & \text { Level of control of accountability } \\
- & \text { Level of risk tolerance } \\
\text { - } & \text { Tendency to be an early adopter } \\
- & \text { Cost orientation } \\
\text { - Tendency for information sharing }\end{array}$ \\
\hline $\begin{array}{l}\text { Mission, Vision, \& } \\
\text { Values }\end{array}$ & $\begin{array}{l}\text { Hospital's objectives, approach to those } \\
\text { objectives, and desired future position }\end{array}$ & $\begin{array}{ll}- & \text { Focus on physician issues } \\
- & \text { Focus on quality goals } \\
- & \text { Focus on population health } \\
- & \text { Emphasis on technology } \\
- & \text { Emphasis on supply chain management } \\
- & \text { Promotion of multidisciplinary care } \\
- & \text { History of physician-hospital collaboration }\end{array}$ \\
\hline Transparency & $\begin{array}{l}\text { Sharing of information with the physician } \\
\text { group }\end{array}$ & $\begin{array}{l}\text { - } \quad \text { Financial performance } \\
\text { Cost of care }\end{array}$ \\
\hline \multicolumn{3}{|l|}{ Strategic Resources } \\
\hline Patient and Payer Mix & $\begin{array}{l}\text { Make-up of patients who have received care } \\
\text { from the hospital }\end{array}$ & - $\quad$ Percentage of Medicaid and Medicare discharges \\
\hline Strategies & $\begin{array}{l}\text { Intangible resources that guide the hospital in } \\
\text { its decision to integrate a physician group }\end{array}$ & 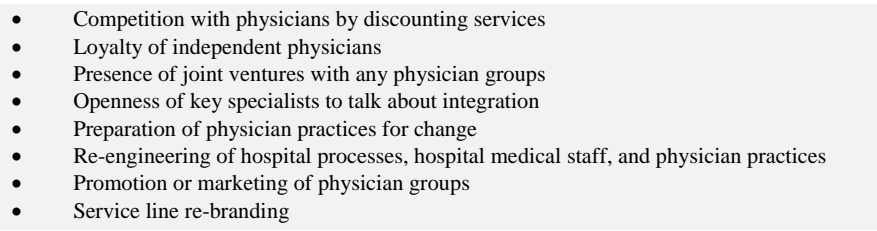 \\
\hline Tangible Resources & Tangible assets used or owned by the hospital & $\begin{array}{ll}- & \text { Physician workforce } \\
- & \text { Registered nurses } \\
- & \text { Physician extenders } \\
- & \text { Support staff (non-clinician hospital staff) } \\
- & \text { Compensation of hospital executives } \\
- & \text { Quality of labor }\end{array}$ \\
\hline $\begin{array}{l}\text { Information } \\
\text { Technology }\end{array}$ & Systems that enable the transfer of information & $\begin{array}{ll}- & \text { Use of health IT in general } \\
- & \text { Investments in health IT } \\
- & \text { Dependence on one IT vendor (vs. multiple) } \\
\text { Trained implementers from IT vendors on-site } \\
\text { Functionalities of IT system (book referrals/consultations, communicate with patients and } \\
\text { physicians, order tests and prescriptions, send reminders, view lab results) }\end{array}$ \\
\hline
\end{tabular}

\subsubsection{Care coordination}

Care coordination was important to physician-system integration, as its mechanisms bridged the players involved. Care coordination, however, had become a dimension of interest only in recent years, given that care coordination processes had been more difficult to measure than structure and outcomes. ${ }^{[63]}$ We identified only seven articles that considered care coordination in their analyses, and all were published in 2010 or after. The four factors transcended all parts of the service delivery chain included: (1) post-acute and outpatient 
care; (2) case management resources; (3) communication; and (4) focus on continuity of care.

Post-Acute and Outpatient Care. The availability of postacute and outpatient facilities and services was defined as the health system's access to services across the care continuum. This included but was not limited to: home care, freestanding outpatient clinics, primary care centers, and urgent care. ${ }^{[54]}$

Case Management Resources. Relatedly, case management was the mechanism through which the patient was transitioned from one service to the next. An example of case management was having an established nurse case/care management with specialized training ${ }^{[19,45]}$ and access to care maps. ${ }^{[50]}$ Case management was further measured by teamwork and use of best practices, standards, and protocols.

Communication. Communication focused on the timeliness of information transfer through multiple pathways. ${ }^{[42]}$ To facilitate care coordination, communication must have occurred between inpatient and outpatient providers, between providers in the same setting, between levels of the organization, and between the patient and caregiver.

Focus on Continuity of Care. Rather than focusing on a service line of care, we found that an important aspect of care coordination was the focus on continuity of care. One article noted that "most clinical process integration appears focused on single diagnoses or conditions rather than integration across all of a patient's medical needs". ${ }^{44]}$

\subsubsection{Health system success}

Health system success was measured using thirteen very factors. To group the factors into more tangible areas of focus, we conducted a cluster analysis, drawing from the Value Chain to differentiate the factors. We established five clusters, finding that they oriented roughly with the Triple Aim of health care - to improve patient experience, to reduce cost per capita, and to improve the health of populations. ${ }^{[64]}$ The clusters also captured the aspect of physician-system integration where it is a business transaction. A MANOVA test indicated that the five clusters were significantly different overall $(p<.001)$. Appendix E provides detailed results of the ANOVA test for significant differences along the factors. In Table 3, we show the thirteen success factors by cluster, along with definitions and the variables we found in the literature that have been used to measure each.

Cluster 1 - Improving Patient Experience of Care. Clusters 1-4 corresponded with the goals of the Triple Aim. Cluster 1 mostly dealt with aspects of improving the patient experience of care and included the factors: efficiency; health system culture; patient experience; and physician engagement. Efficiency clustered with the above factors, but based on the way efficiency was described in the literature (ability to minimize operational transaction costs), it was unclear how it directly impacted patient experience, appearing to contribute more to resource management.

The factors in this cluster tended to be associated with the organizational structure, organizational culture, strategic resources, and point-of-service components of the Value Chain (see Appendix E). Namely, when examining one of these factors as dependent variables, past studies concurrently employed independent variables that described the structure, culture, resources of physician groups and/or hospitals, as well as point-of-service type measures of care coordination.

Cluster 2 - Reducing Per Capita Cost (Spending). Cluster 2 focused on reducing per capita cost. It contained only one success measure: financial performance. Financial performance was the revenue generated by the health system. This described the earnings of the health system post-integration and could be considered using direct (i.e., provision of a service ${ }^{[15]}$ ) and indirect measures (i.e., rates of payer discounts $\left.{ }^{[15,20,44]}\right)$. The factors in this cluster tended to be associated with the structure, culture, resource, and afterservice components of the Value Chain.

Cluster 3 - Reducing Per Capita Cost (Revenue). Cluster 3 also focused on reducing per capita cost, but contrary to Cluster 3, the factors of Cluster 4 dealt more with revenue generation. These factors included: health services utilization; total cost of care; and IT utilization. The factors considered how much patients used the health system via administrative and patient care charges. Of note, total cost of care was the most cited success factor. It was unclear, why IT utilization clustered with the other two factors, as it was controversial whether IT implementations resulted in health system cost savings or cost generation. ${ }^{[65,66]}$ Cluster 3 factors drew only from the structure and resource components of the Value Chain. This suggests that successful cost reduction stemmed from reduced transaction costs between the structural and resource factors of physician groups and hospitals.

Cluster 4 - Improving the Health of Populations. Cluster 4 was aligned with the last Triple Aim, improving the health of populations. Cluster 4 consisted solely of the factor: quality and safety, which was the degree to which health services increased the likelihood of desired health outcomes and were consistent with current professional knowledge. This factor considered at multiple levels: health system, community and population level, and individual. Per the ANOVA test results, Cluster 4 tended to be associated with all parts of the Value Chain except after-service. However, it was not clear why after-service did not play a role in determining this cluster. 
Table 3. Health system success factors relevant to physician-system integration

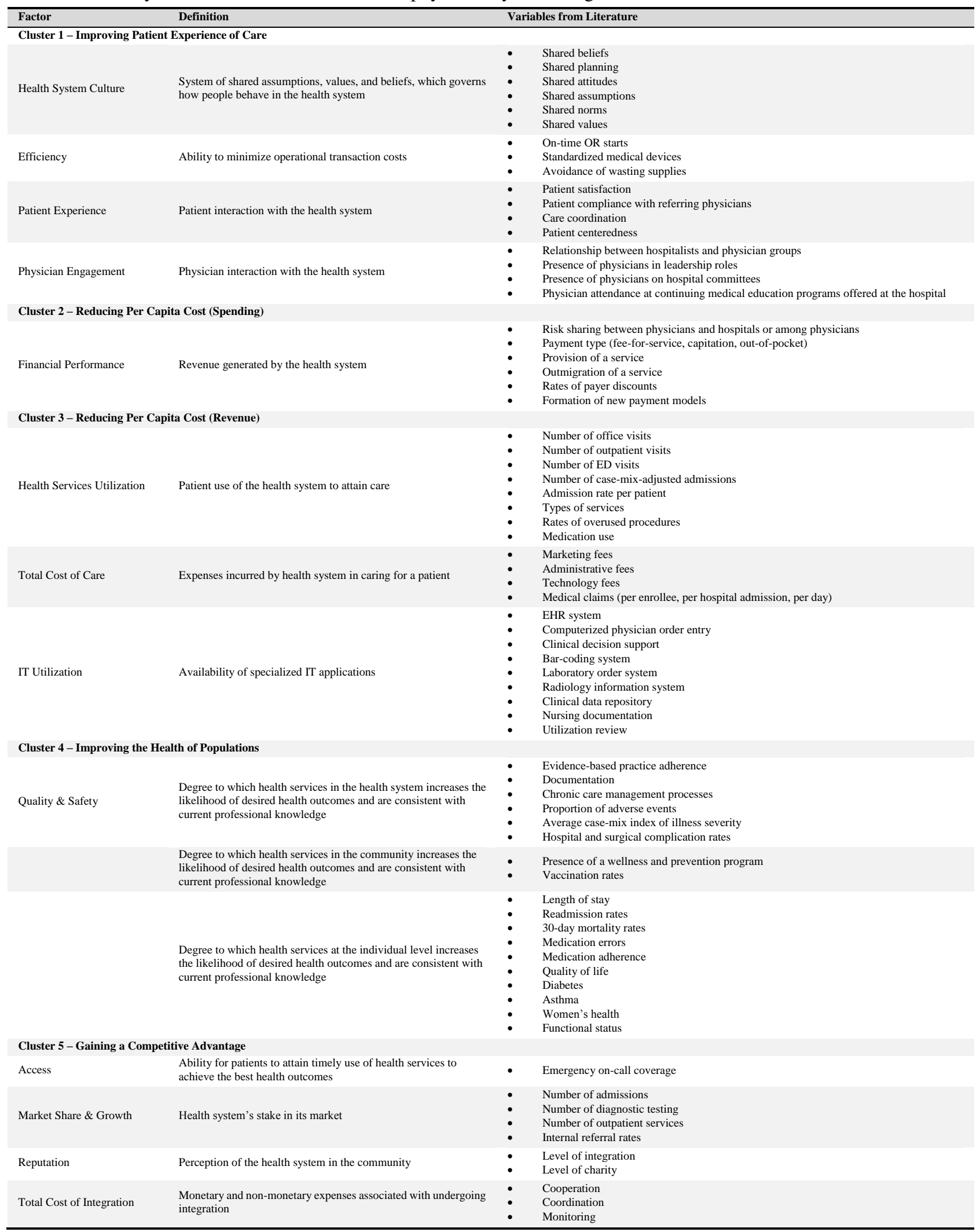


Cluster 5 - Gaining a Competitive Advantage. Cluster 5 was comprised of success factors that were outward-facing and oriented toward giving the integrated health system a competitive advantage. The Cluster 5 factors were: access; market share and growth; reputation; and total cost of integration. It was important to look at these factors internally ${ }^{[45]}$ and externally, ${ }^{[39]}$ where possible. For example, reputation, which was the perception of the health system in the community, could be measured by how charitable the health system was, as seen by its patients and employees. ${ }^{[39]}$ The factors in this cluster tended to be associated with the organizational structure and pre-service components of the Value Chain.

\subsubsection{Landscape of physician-system integration model}

We present the resulting conceptual model - the landscape of physician-system integration (LOPSI) model (see Figure 2), which synthesizes 48 organizational factors affecting health system success. In the model, the physician group of interest is affiliated with a hospital that is part of a health system. The physician group is part of a larger network of physicians who are on the hospital's medical staff, which may include other physician groups and/or independent physicians. Both sets of physicians contribute to the success of the hospital, as well as to the success of the health system. All are influenced and interact with ACOs, health plans, and the environment. Recognizing that resource limitations make it impractical and often impossible to evaluate all aspects of integration, we aligned the factors with the Value Chain to allow future users of the model to hone their approaches on outcome(s) of interest.

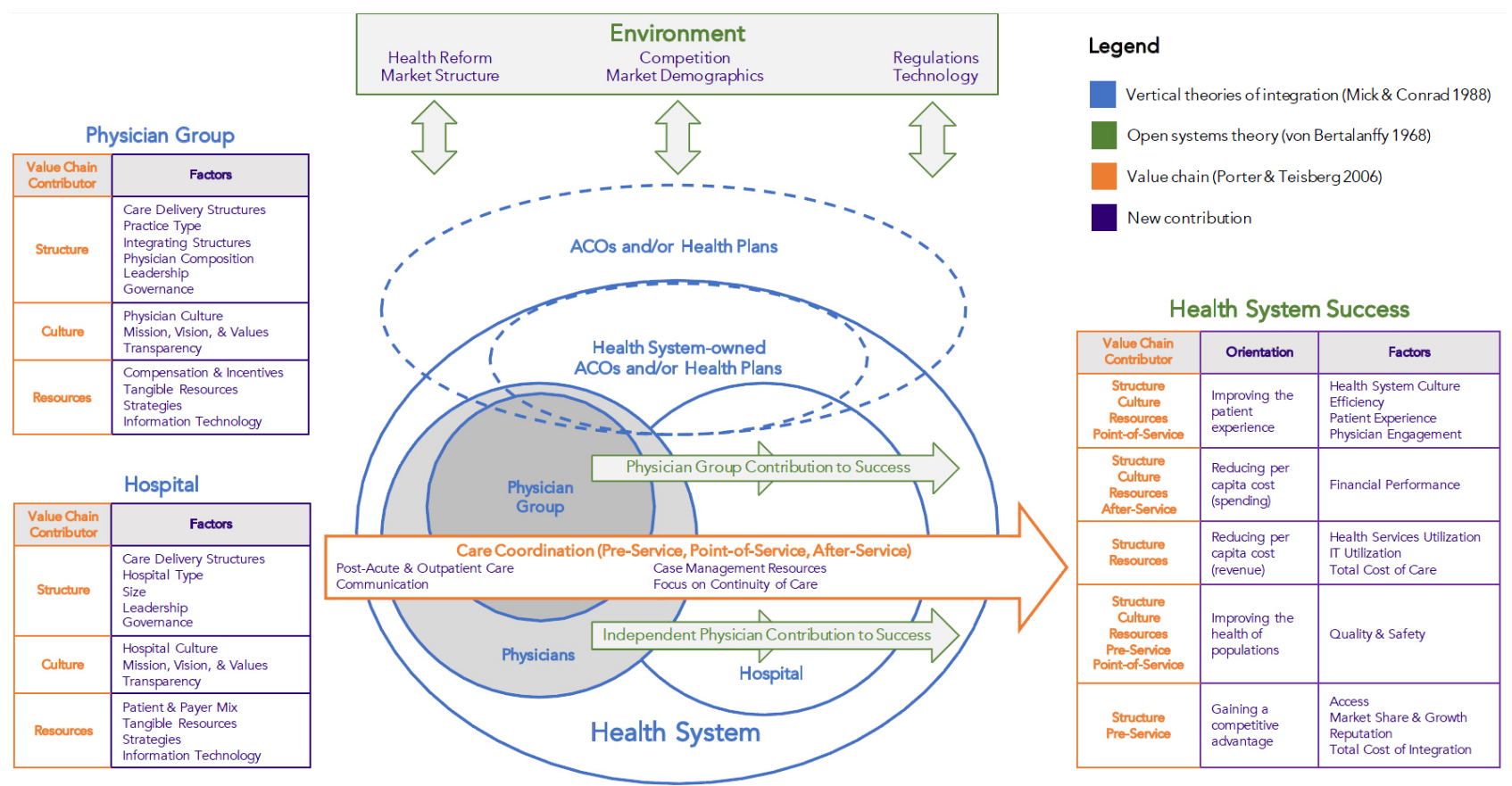

Figure 2. Conceptual model of the landscape of physician-system integration (LOPSI), based on a scoping review and cluster analysis of empirical research studies, 2005-2016. Dotted lines denote that accountable care organizations (ACOs) and health plans can be owned by and/or independent of the health system.

\section{Discussion}

This scoping review confirmed earlier beliefs that physiciansystem integration is complex due to its multiple internal and external layers. ${ }^{[2,19,67,68]}$ Our study also revealed potential deficits in the past evidence base. First, only a fraction (37.9\%) of the included empirical articles used organizational theory to define their approach. The absence of theory in empirical research may lead to a potential imbalance in analysis; future research should consider employing a combination of internal and external theories. The prominent use of bargaining-market power theory aligned with our application of open systems theory to define the external environment of our conceptual model. Likewise, elements of transaction cost theory aligned with our application of the Value Chain to define the internal environment. In two reviewed articles, ${ }^{[13,37]}$ researchers used bargaining-market power theory and transaction cost theory together for this purpose. Our approach to use open systems theory and the Value Chain was thus consistent with the past literature, however broader. The second potential deficit in the past evidence base is that 
process measures (i.e., care coordination mechanisms) were lacking, despite their important role in facilitating care between physicians and health systems. We recommend more research to define the measures of care coordination.

Health care executives, policymakers, and researchers should carefully consider and effectively communicate the multiple factors that influence integration. As evidenced by our scoping review, physician-system integration is a multi-faceted change for a health system. Practitioners and researchers alike posit that to obtain success, the effective execution of change is more important than the strategy for that change. ${ }^{[69]}$ A health system cannot simply adopt a generic strategy to affiliate with a physician group; it must think through the factors that affect the execution of the affiliation. What are the factors of the environment? The physician group? The hospital? How will care be coordinated between the two entities? It is only through a collective approach that considers all these dimensions that we can uncover the major determinants of health system success.

Our study was not without limitations. First, we cannot be sure that we identified all relevant articles; however, we used a broad search strategy that included a review of bibliographies to ensure that pertinent studies were captured. Second, we included only empirical articles from 2005-2016, which excludes seminal works from the 1960s and 1970s and

\section{REFERENCES}

[1] Hwang W, Andrie J, LaClair M, et al. Two visions of clinical integration: perspectives from health system leaders. J Hosp Adm. 2014 Dec 5 [cited 2019 Jul 29]; 4(1): 36. https ://doi .org/10.5430/ jha.v4n1p36

[2] Armitage GD, Suter E, Oelke ND, et al. Health systems integration: state of the evidence. Int J Integr Care. 2009 Jun 17 [cited 2017 Feb 9] 9(2). PMid:19590762. https://doi.org/10.5334/ijic.316

[3] Conrad DA, Shortell SM. Integrated Health Systems: Promise and Performance. Front Health Serv Manage. 1996; 13(1): 3-40. https://doi.org/10.1097/01974520-199607000-00002

[4] Burns LR, Pauly MV. Integrated Delivery Networks: A Detour on the Road to Integrated Health Care? Health Aff. 2002; 21: 128-43. PMid: 12117123. https://doi.org/10.1377/hlthaff.21.4.128

[5] Shortell SM, Gillies RR, Anderson DA. The New World of Managed Care: Creating Organized Delivery Systems. Health Aff. 1994; 13(5): 46-64. PMid: 7868039. https://doi.org/10.1377/hlth aff.13.5.46

[6] McCarthy D, Mueller K. Organizing for Higher Performance: Case Studies of Organized Delivery Systems. Commonw Fund. 2009; 21(1288): 1-38.

[7] Goes JB, Zhan C. The Effects of Hospital-Physician Integration Strategies on Hospital Financial Performance. Health Serv Res. 1995; 30(4): 507 theoretical articles. The time frame was necessary to allow for feasibility, and we attempted to ensure rigor by grounding our work in theoretical frameworks and triangulating our results with empirical studies. ${ }^{[70]}$ Third, cluster analysis, while frequently used in management research since the 1970s, has known problems that stem from the analysis' reliance on researcher judgment. ${ }^{[71]}$ To maximize value from this technique, we ensured the validity of our clusters by triangulating findings with theory. Triangulation helps apply the strengths of one method to complement the strengths of another, neutralizing some of the latter's weaknesses. ${ }^{[30]}$ Fourth, in developing our conceptual model, we recognized that this topic requires practice-validation; when have hence tested the model with practitioners in concurrent work ( $\mathrm{Au}$ thor, 2019; redacted for peer-review).

\section{ACKNOWLEDGements}

This project was supported by grant number R36HS024895 from the Agency for Healthcare Research and Quality. The content is solely the responsibility of the authors and does not necessarily represent the official views of the Agency for Healthcare Research and Quality. Preliminary findings were presented as a poster at the AcademyHealth Annual Meeting, June 2018, in Seattle, WA.

\section{CONFLICTS OF INTEREST DisClosure}

The authors declare they have no conflicts of interest.
[8] Snail TS, Robinson JC. Organizational Diversification in the American Hospital. Annu Rev Public Health. 1998; 19: 417-53. PMid: 9611626. https://doi.org/10.1146/annurev.publhe alth.19.1.417

[9] Trybou J, Gemmel P, Annemans L. The Ties That Bind: An Integrative Framework of Physician-Hospital Alignment. BMC Health Serv Res. 2011; 11(1): 36. PMid: 21324128. https://doi.org/10.1 186/1472-6963-11-36

[10] Ciliberto F, Dranove D. The Effect of Physician-Hospital Affiliations on Hospital Prices in California. J Health Econ. 2006; 25(1): 2938. PMid: 16352360 . https ://doi.org/10.1016/j.jhealeco .2005 .04 .008

[11] Madison K. Hospital-Physician Affiliations and Patient Treatments, Expenditures, and Outcomes. Health Serv Res [Internet]. 2004 Apr [cited 2018 Apr 23]; 39(2): 257-78. PMid: 15032954. https: //doi.org/10.1111/j.1475-6773.2004.00227.x

[12] Scott KW, Orav EJ, Cutler DM, et al. Changes in Hospital-Physician Affiliations in U.S. Hospitals and Their Effect on Quality of Care. Ann Intern Med. 2017 [cited 2017 Sep 13]; 166(1): 1-8. PMid: 27654704. https://doi.org/10.7326/M16-0125

[13] Baker LC, Bundorf MK, Kessler DP. Vertical Integration: Hospital Ownership of Physician Practices is Associated with Higher Prices and Spending. Health Aff. 2014; 33(5): 756-63. PMid: 24799571. https://doi.org/10.1377/hlthaff.2013.1279 
[14] Gans DN. Perspective is Everything: Look Beyond Reported Losses. MGMA Connex. 2012; 12(10): 17-9.

[15] Robinson JC, Miller K. Total Expenditures per Patient in HospitalOwned and Physician-Owned Physician Organizations in California. JAMA. 2014 Oct 22 [cited 2016 Nov 30]; 312(16): 1663. PMid: 25335148. https://doi.org/10.1001/jama.2014.14072

[16] Kocher R, Sahni NR. Hospitals' Race to Employ Physicians-The Logic Behind a Money-losing Proposition. N Engl J Med. 2011; 364(19): 1790-3. PMid: 21449774. https://doi.org/10.1056/ NEJMp1101959

[17] Burns LR, Muller RW. Hospital-Physician Collaboration: Landscape of Economic Integration and Impact on Clinical Integration. Milbank Q. 2008 Sep [cited 2015 Oct 12]; 86(3): 375-434. PMid: 18798884. https://doi.org/10.1111/j.1468-0009.2008.00527.x

[18] Deloitte Center for Health Solutions. Deloitte 2013 Survey of U.S. Physicians: Physician Perspectives About Health Care Reform and the Future of the Medical Profession. Washington, DC; 2013. Available from: http://www2.deloitte.com/content/dam/ Deloitte/us/Documents/life-sciences-health-care/us -lshc-deloitte-2013-physician-survey-10012014.pdf

[19] Hwang W, Change J, LaClair M, et al. Effects of integrated delivery system on cost and quality. Am J Manag Care. 2013; 19(5): e175-84.

[20] Trybou J, Gemmel P, Annemans L. Provider accountability as a driving force towards physician-hospital integration: a systematic review. Int J Integr Care. 2015 Apr 1 [cited 2017 Aug 10]; 15(1). PMid: 26034469. https://doi.org/10.5334/ijic. 1582

[21] Okhuysen G, Bonardi JP. Editor's Comments: The Challenges of Building Theory by Combining Lenses [Internet]. Vol. 36, The Academy of Management Review. Academy of Management; 2011 [cited 2017 Oct 16]. 6-11 p. https://doi.org/10.5465/amr. 36 .1.zok006

[22] Mick SS, Conrad DA. The Decision to Integrate Vertically in Health Care Organizations. J Healthc Manag. 1988; 33(3): 345.

[23] Von Bertalanffy L. General System Theory: Foundations, Development, Applications. New York: George Braziller, Inc.; 1968. 296 p.

[24] Miller RH. Health System Integration: A Means to an End. Health Aff. 1996 May 1 [cited 2015 Nov 19]; 15(2): 92-106. PMid: 8690393. https://doi.org/10.1377/hlthaff.15.2.92

[25] Porter ME, Teisberg EO. Redefining Health Care: Creating Valuebased Competition on Results. Boston, MA: Harvard Business Press; 2006.

[26] Ginter PM, Duncan JW, Swayne LE. Strategic Management of Health Care Organizations. Hoboken, NJ: John Wiley \& Sons, Inc.; 2013. $476 \mathrm{p}$.

[27] Munn Z, Peters MDJ, Stern C, et al. Systematic review or scoping review? Guidance for authors when choosing between a systematic or scoping review approach. BMC Med Res Methodol. 2018 Dec 19 [cited 2019 Jul 23]; 18(1): 143. PMid: 30453902. https://doi.org/10.1186/s12874-018-0611-x

[28] Clarivate Analytics. EndNote. New York, NY: Clarivate Analytics; 2016.

[29] Strauss A, Corbin JM. Basics of Qualitative Research: Grounded Theory Procedures and Techniques. Thousand Oaks, CA: Sage Publications, Inc; 1990.

[30] Denzin NK. The Research Act. 3rd Ed. New York, NY: McGraw Hill; 1989.

[31] SocioCultural Research Consultants. Dedoose. Los Angeles, CA; 2019. Available from: http://www. dedoose.com

[32] Kaufman L, Rousseeuw PJ. Finding Groups in Data: An Introduction to Cluster Analysis. Vol. 344. New York: John Wiley \& Sons; 1990. https://doi.org/10.1002/9780470316801
[33] Marlin D, Sun M, Huonker JW. Strategic Groups and Performance in the Nursing Home Industry: A Reexamination. Med Care Res Rev. 1999; 56(2): 156-76. PMid: 10373722. https://doi.org/10.1 177/107755879905600203

[34] Dubois CA, D'Amour D, Tchouaket E, et al. A Taxonomy of Nursing Care Organization Models in Hospitals. BMC Health Serv Res. 2012; 12(1): 286. PMid: 22929127. https://doi.org/10.1186/1472 -6963-12-286

[35] Xue D, Zhou P, Bundorf MK, et al. The Association of Strategic Group and Organizational Culture with Hospital Performance in China. Health Care Manage Rev. 2013; 38(3): 258-70. PMid: 22872139. https://doi.org/10.1097/HMR.0b013e3182678f $9 \mathrm{a}$

[36] StataCorp LP. Stata Statistical Software: Release 13. College Station, TX; 2013.

[37] Cuellar AE, Gertler PJ. Strategic Integration of Hospitals and Physicians. J Health Econ. 2006; 25(1): 1-28. PMid: 16309766. https: //doi.org/10.1016/j.jhealeco.2005.04.009

[38] Mehrotra A. Do Integrated Medical Groups Provide Higher-Quality Medical Care than Individual Practice Associations? Ann Intern Med. 2006 Dec 5 [cited 2015 Nov 21]; 145(11): 826. PMid: 17146067. https://doi.org/10.7326/0003-4819-145-11-2 00612050-00007

[39] Berenson RA, Ginsburg PB, May JH. Hospital-physicians relations: cooperation, competition, or separation? Health Aff (Millwood). 2007 Jan 1 [cited 2015 Nov 20]; 26(1): w31-43. PMid: 17148489. https://doi.org/10.1377/hlthaff.26.1.w31

[40] Casalino LP, November EA, Berenson RA, et al. Hospital-physician relations: two tracks and the decline of the voluntary medical staff model. Health Aff. 2008 Sep 1 [cited 2017 Sep 5]; 27(5): 130514. PMid: 18780916 . https://doi.org/10.1377/hlthaff. 27 .5 .1305

[41] McCullough JS, Snir EM. Monitoring technology and firm boundaries: Physician-hospital integration and technology utilization. J Health Econ. 2010 May [cited 2017 Aug 31]; 29(3): 457-67. PMid: 20398953. https://doi.org/10.1016/j.jhealeco.2010.03 .003

[42] Strandberg-Larsen M, Schiøtz ML, Silver JD, et al. Is the Kaiser Permanente model superior in terms of clinical integration?: A comparative study of Kaiser Permanente, Northern California and the Danish healthcare system. BMC Health Serv Res. 2010 Dec 8 [cited 2017 Sep 5]; 10(1): 91. PMid: 20374667. https://doi.org/10 .1186/1472-6963-10-91

[43] Felland LE, Grossman JM, Tu HT. Key findings from HSC's 2010 site visits: health care markets weather economic downturn, brace for health reform. Cent Stud Heal Syst Chang. 2011; (135): 1-8.

[44] O'Malley AS, Bond AM, Berenson RA. Rising hospital employment of physicians: better quality, higher costs? Cent Stud Heal Syst Chang. 2011 [cited 2017 Sep 5]; (136): 1-4. Available from: http://www.hschange.org/CONTENT/1230/1230.pdf

[45] Evans JM, Baker RG, Berta W. The Evolution of Integrated Health Care Strategies. Adv Health Care Manag. 2013 [cited 2017 Sep 5]; 15: 125-61. https://doi.org/10.1108/S1474-8231(2013)0 000015011

[46] Kauk JR, Bray TJ. Orthopaedist-hospital alignment in a community setting. Clin Orthop Relat Res. 2013 Jun [cited 2017 Sep 5]; 471(6): 1837-45. PMid: 23430719. https://doi.org/10.1007/s11999 -013-2805-1

[47] Lammers E. The Effect of Hospital-Physician Integration on Health Information Technology Adoption. Health Econ. 2013 [cited 2017 Aug 31]; 22: 1215-29. PMid: 23055450. https://doi .org/10.1 002/hec. 2878 
[48] McWilliams JM, Chernew ME, Zaslavsky AM, et al. Delivery system integration and health care spending and quality for Medicare beneficiaries. JAMA Intern Med. 2013 Aug 12 [cited 2017 Sep 5]; 173(15): 1447-56. PMid: 23780467. https://doi.org/10.100 1/jamainternmed.2013.6886

[49] Page AE, Butler CA, Bozic KJ. Factors driving physician-hospital alignment in orthopaedic surgery. Clin Orthop Relat Res. 2013 Jun [cited 2017 Sep 5]; 471(6): 1809-17. PMid: 23229427. https: //doi.org/10.1007/s11999-012-2730-8

[50] Sowers KW, Newman PR, Langdon JC. Evolution of physicianhospital alignment models: a case study of comanagement. Clin Orthop Relat Res. 2013 Jun [cited 2017 Sep 5]; 471(6): 1818-23. PMid: 23494183. https://doi .org/10.1007/s11999-013-2911-0

[51] Cho NE, Chang J, Atems B. The effects of health information technology adoption and hospital-physician integration on hospital efficiency. Am J Manag Care. 2014 Nov [cited 2017 Sep 5]; $20(11 \mathrm{Spec}$ No. 17): eSP9-15. Available from: http://www.ncbi.nlm.nih.gov/pub med/25811821

[52] Janus K, Brown LD. Physician integration revisited-An exploratory study of monetary and professional incentives in three countries. Health Policy. 2014 Oct [cited 2017 Sep 5]; 118(1): 14-23. PMid: 25190050. https://doi.org/10.1016/j.healthpol.2014.0 8.001

[53] Cho NE. Costs of Physician-Hospital Integration. Medicine (Baltimore). 2015 Oct [cited 2017 Sep 5]; 94(42): e1762. PMid: 26496300. https://doi.org/10.1097/MD.0000000000001762

[54] Chukmaitov A, Harless DW, Bazzoli GJ, et al. Delivery system characteristics and their association with quality and costs of care: Implications for accountable care organizations. Health Care Manage Rev. 2015 [cited 2017 Sep 5]; 40(2): 92-103. PMid: 24566250. https://doi.org/10.1097/HMR.0000000000000014

[55] Neprash HT, Chernew ME, Hicks AL, et al. Association of Financial Integration Between Physicians and Hospitals with Commercial Health Care Prices. JAMA Intern Med. 2015 Dec 1 [cited 2017 Aug 31]; 175(12): 1932. PMid: 26501217. https://doi.org/10.100 $1 /$ jamainternmed.2015.4610

[56] Song Z, Wallace J, Neprash HT, et al. Medicare Fee Cuts and Cardiologist-Hospital Integration. JAMA Intern Med. 2015 Jul 1 [cited 2017 Sep 5]; 175(7): 1229. PMid: 26011666. https://doi. org/10.1001/jamainternmed.2015.2017

[57] Baker LC, Bundorf MK, Kessler DP. The effect of hospital/physician integration on hospital choice. J Health Econ. 2016 Dec [cited 2017 Aug 16]; 50: 1-8. Available from: http://linkinghub.elsevie r.com/retrieve/pii/S0167629616301679

[58] Everson J, Lee SYD, Adler-Milstein J. Achieving Adherence to Evidence-Based Practices. Med Care Res Rev. 2016 Dec 3 [cited 2017 Aug 31]; 73(6): 724-51. PMid: 26739594. https ://doi.or g/10.1177/1077558715625011
[59] Lanese B. Implementation of the affordable care act: a case study of a service line co-management company. J Health Organ Manag. 2016 Sep 19 [cited 2017 Sep 5]; 30(6): 818-35. PMid: 27681019. https://doi.org/10.1108/JHOM-09-2015-0145

[60] Coase RH. The Nature of the Firm. Economica. 1937 Nov [cited 2015 Jan 9]; 4(16): 386-405. https ://doi .org/10.1111/j. 14 68-0335.1937.tb00002.x

[61] Williamson OE. The Economics of Organization: The Transaction Cost Approach. Am J Sociol. 1981; 87(3): 548-77. https: //doi.org/10.1086/227496

[62] Gal-Or E. The profitability of vertical mergers between hospitals and physician practices. J Health Econ. 1999 Oct [cited 2017 Aug 31]; 18(5): 623-54. https://doi .org/10.1016/S0167-6296(99)0 0013-2

[63] Hoenig H, Duncan PW, Horner RD, et al. Structure, Process, and Outcomes in Stroke Rehabilitation. Med Care. 2002 [cited 2017 Sep 22]; 40(11): 1036-47. PMid: 12409849. https://doi.org/10.1 097/00005650-200211000-00005

[64] Berwick DM, Nolan TW, Whittington J. The Triple Aim: Care, Health, and Cost. Health Aff. 2008 May 1 [cited 2016 Jun 22]; 27(3): 759-69. PMid: 18474969. https://doi.org/10.1377/hlthaff . 27.3 .759

[65] Congressional Budget Office. Evidence on the Costs and Benefits of Health Information Technology. 2008. Available from: http://ww w. cbo.gov/ftpdocs/91xx/doc9168/05-20-HealthIT .pdf

[66] Zlabek JA, Wickus JW, Mathiason MA. Early cost and safety benefits of an inpatient electronic health record. J Am Med Informatics Assoc. 2011 Mar 1 [cited 2017 Nov 1]; 18(2): 169-72. PMid: 21292703. https://doi.org/10.1136/jamia.2010.007229

[67] Kodner DL. All together now: a conceptual exploration of integrated care. Healthc Q. 2009; 13: 6-15. PMid: 20057243. https: //doi.org/10.12927/hcq. 2009.21091

[68] Strandberg-Larsen M, Krasnik A. Measurement of integrated healthcare delivery: a systematic review of methods and future research directions. Int J Integr Care. 2009 Feb 4 [cited 2017 Apr 27]; 9(1). https://doi.org/10.5334/ijic.305

[69] Gillies RR, Shortell SM, Anderson DA, et al. Conceptualizing and Measuring Integration: Findings From the Health Systems Integration Study. J Healthc Manag. 1993; 38(4): 467.

[70] Creswell JW, Clark VLP. Designing and Conducting Mixed Methods Research. 4th Ed. Thousand Oaks, CA: SAGE Publications, Inc; 2017. $520 \mathrm{p}$.

[71] Ketchen DJ, Jr., Shook CL. The Application of Cluster Analysis in Strategic Management Research: An Analysis and Critique. Vol. 17, Strategic Management Journal. Wiley; 1996 [cited 2017 Oct 27]. 44158 p. https://doi.org/10.1002/(SICI) 1097-0266(199606 ) $17: 6<441::$ AID-SMJ819>3.0.CO;2-G 